\title{
Static mechanical properties and mechanism of C200 ultra-high performance concrete (UHPC) containing coarse aggregates
}

https://doi.org/10.1515/secm-2020-0018

Received Feb 03, 2020; accepted May 03, 2020

\begin{abstract}
In this paper, C200 ultra-high performance concrete (UHPC) containing coarse aggregate was prepared. Firstly, four different maximum size and three different type of coarse aggregate having significant differences in strength, surface texture, porosity and absorption were used to prepared the mixtures. Secondly, the effect of maximum size and type of coarse aggregate on the workability of the fresh UHPC and the mechanical behaviour of harden UHPC were investigated. Finally, a series micro-tests including mercury intrusion porosimetry (MIP), scanning electron microscope (SEM), X-ray diffraction (XRD) were conducted and the mechanism of the C200 UHPC were discussed.

The results show that the type and maximum size of coarse aggregate have significant effect on the workability and mechanical properties of C200 UHPC. The basalt coarse aggregate with maximum size of $10 \mathrm{~mm}$ can be used to prepare the C200 UHPC. The compressive strength and flexural strength of the C200 UHPC is 203MPa and 46MPa at 90 day, respectively. Besides, the micro-tests data show that the C200 UHPC has a compacted matrix and strong interface transition zone (ITZ), which make the aggregate potential strength fully used.
\end{abstract}

Keywords: C200 concrete, UHPC, coarse aggregate, mechanical properties, ITZ

\footnotetext{
^Corresponding Author: Zhang Wenhua: Department of Civil Engineering, Nanjing Forestry University, Nanjing, China, 210037; Email: zhangwenhua2009@163.com

Lv Yujing, Wu Fan, Wu Peipei, Zeng Weizhao, Yang Fenghao: Department of Civil Engineering, Nanjing Forestry University, Nanjing, China, 210037
}

ə Open Access. ( 2020 L. Yujing et al., published by De Gruyter. (cc) BY License

\section{Introduction}

Reactive powder concrete (RPC) is an advanced cement based material, which can be divided into RPC200 and RPC800 [1-4]. The compressive strength of RPC200 is between $150 \mathrm{MPa}$ and $200 \mathrm{MPa}$, flexural strength ranges from $20 \mathrm{MPa}$ to $50 \mathrm{MPa}$ and fracture energies varies between $15,000 \mathrm{~J} / \mathrm{m}^{2}$ and $40,000 \mathrm{~J} / \mathrm{m}^{2}[1,2]$. Obviously, RPC possess the ultra-high mechanical properties, which has a great potential prospect in the fields of civil, pavement, bridge and protective shelter of military engineering $[5,6]$.

It is well known that the RPC is composited of a high dosage of cement (generally over $800 \mathrm{~kg} / \mathrm{m}^{3}$ ), very fine powder (such as crushed quartzite and silica fume) and steel fiber [1, 2]. Obviously, these expensive raw materials are responsible for the high production cost. In addition, the rigorous curing regimes usually employed in the fabrication of RPC $\left(200^{\circ} \mathrm{C}\right.$ autoclave curing or $90^{\circ} \mathrm{C}$ heating curing) result in a low production efficiency and high energy consumption. Moreover, for the enhancement homogeneity, the coarse aggregates are eliminated in RPC [1]. However, the coarse aggregate is the main composite part in normal strength concrete, which is up to approximately 40 percent of the total volume. The elimination of the coarse aggregate means the much higher amount of cementitious dosage in the RPC. This may leads to sharp increase in shrinkage, creep, hydration heat and the production cost of the RPC. Furthermore, increased shrinkage characteristics and high sensitive microcracking may reduce its early age and hardened performance. Therefore, how to reduce production cost and energy consumption, simplify the manufacturing process, eliminating the negative effective caused by the high amount of cementitious dosage are the key problems for the application of RPC in practical engineering.

Our previous studies [6-10] have been discussed the preparation of C200 ultra-high performance (UHPC) as the following methods. Firstly, a large amount of Portland cement ( $\mathrm{PC} \geq 50 \%$ ) was replaced by a cheap industrial mineral admixture of fly ash (FA), slag (SL) and silica fume 
Table 1: Chemical composition and physical properties of cementitious materials

\begin{tabular}{lllll}
\hline Chemical composition (\%) & $\mathrm{PC}$ & $\mathrm{SF}$ & $\mathrm{FA}$ & $\mathrm{SL}$ \\
$\mathrm{SiO}_{2}$ & 20.6 & 94.5 & 55.0 & 34.2 \\
$\mathrm{Fe}_{2} \mathrm{O}_{3}$ & 4.4 & 0.8 & 5.9 & 0.4 \\
$\mathrm{MgO}$ & 5.0 & 0.3 & 31.3 & 14.2 \\
$\mathrm{Al}_{2} \mathrm{O}_{3}$ & 5.0 & 0.3 & 31.3 & 14.2 \\
$\mathrm{CaO}_{\mathrm{SO}}$ & 65.1 & 0.5 & 3.9 & 41.7 \\
$\mathrm{LOI}$ & 2.2 & 0.8 & 1.5 & 1.0 \\
Specific surface area $\left(\mathrm{m}^{2} / \mathrm{kg}\right)$ & 1.3 & 1.0 & 1.0 & 1.7 \\
Specific gravity $\left(\mathrm{k} / \mathrm{cm}^{3}\right)$ & 417 & 2200 & 686 & 766 \\
\hline
\end{tabular}

Table 2: Properties of coarse aggregates

\begin{tabular}{llllll}
\hline aggregate & Compressive & Relative density & Porosity $(\%)$ & Maximum size $(\mathrm{mm})$ & water absorption (\% of dry mass) \\
\hline Granitic & 144 & 2.64 & 0.13 & 10 & 0.28 \\
Basalt & 203 & 2.90 & 0.45 & 10 & 0.54 \\
Basalt & 203 & 2.90 & 0.45 & 5 & 0.54 \\
Basalt & 203 & 2.90 & 0.45 & 10 & 0.54 \\
Basalt & 203 & 2.90 & 0.45 & 15 & 0.54 \\
Basalt & 203 & 2.90 & 0.45 & 20 & 0.54 \\
Iron ore & 192 & 4.80 & 0.26 & 10 & 2.20 \\
\hline
\end{tabular}

(SF). Secondly, the natural river sand with the maximum diameter of $3 \mathrm{~mm}$ was substituted for the costly ultra-fine quartz sand. Finally, the standard curing (20 and 100\% relative humidity) took the place of 200 autoclave curing or 90 heating curing. According to the above method, the C200 UHPC with lower energy consumption, lower production cost and easier operation was successfully prepared.

In this paper, production of C200 UHPC containing coarse aggregate without any performance loss compared to the conventional RPC was investigated. Firstly, four different maximum size and three different type of coarse aggregate having significant differences in strength, surface texture, porosity and absorption were used to prepared the mixtures. Secondly, the effect of maximum size and type of coarse aggregate on the workability of the fresh UHPC and the mechanical behaviour of harden UHPC were investigated. Finally, a series micro-tests including mercury intrusion porosimetry (MIP), scanning electron microscope (SEM), X-ray diffraction (XRD) were conducted and the mechanism of the green C200 UHPC were discussed.

\section{Experimental}

\subsection{Raw materials}

Four types of cementitious materials were used in this study: Portland cement (PC) with 28 days of compressive strength of 68.9MPa, silica fume (SF), fly ash (FA) and slag (SL). Their chemical compositions and physical properties are shown in Table 1.

The natural river sand with the maximum size of $3 \mathrm{~mm}$ was used to replace the ultra-fine quartz sand, which is a necessary component to produce RPC reported by published literatures. Three different types of coarse aggregate were used: crushed granitic (CG), crushed basalt (CB) and crushed iron ore (CI). These aggregates were selected because they present significant differences in strength, surface texture, porosity and absorption and bond strength. The CG presents irregular shape, rough texture, and low absorption. The $\mathrm{CB}$ also has an irregular shape and rough texture. The $\mathrm{CI}$ has a rough surface texture and the highest density. The same particle size distribution was adopted with a maximum aggregate size of $10 \mathrm{~mm}$. Compressive strength, relative density, porosity and water absorption ratio index of the aggregate rocks were presented in $\mathrm{Ta}$ ble 2 . 
Table 3: Mixtures proportions $\left(\mathrm{kg} / \mathrm{m}^{3}\right)$

\begin{tabular}{lllllllllll}
\hline Mix No & water & Cement & $\begin{array}{l}\text { Silica } \\
\text { fume }\end{array}$ & $\begin{array}{l}\text { Fly } \\
\text { ash }\end{array}$ & Slag & Sand & $\begin{array}{l}\text { Coarse } \\
\text { aggregate }\end{array}$ & $\begin{array}{l}\text { Steel } \\
\text { fiber }\end{array}$ & SP & $\begin{array}{l}\text { Maximum of aggregate } \\
\text { size }(\mathrm{mm})\end{array}$ \\
\hline RM & 164 & 512 & 102.4 & 204.8 & 204.8 & 1024 & - & 300 & 25.6 & - \\
AT-G & 128 & 400 & 80 & 160 & 160 & 800 & 728 & 234 & 20 & 10 \\
AT-B & 128 & 400 & 80 & 160 & 160 & 800 & 800 & 234 & 20 & 10 \\
AT-I & 128 & 400 & 80 & 160 & 160 & 800 & 1335 & 234 & 20 & 10 \\
AS-10 & 128 & 400 & 80 & 160 & 160 & 800 & 800 & 234 & 20 & 10 \\
AS-15 & 128 & 400 & 80 & 160 & 160 & 800 & 800 & 234 & 20 & 15 \\
AS-20 & 128 & 400 & 80 & 160 & 160 & 800 & 800 & 234 & 20 & 20 \\
\hline
\end{tabular}

\subsection{Mix-design}

Seven mixtures, one reference mixture (RM) without coarse aggregate and six mixtures with different coarse aggregates were designed. The water-binder ratio and sandbinder ratio of all mixtures was 0.16 and 1.0, respectively. For cementitious binder, 50\% of Portland cement was replaced by ternary mineral admixtures composited of $10 \%$ silica fume, $20 \%$ fly ash and $20 \%$ slag. A polycarboxylic type superplasticizer with water reducing ratio of $40 \%$ was adopted to ensure the workability. The dosage of superplasticizer was kept at $2.5 \%$ weight of total binder. To avoid brittle fracture, $3 \%$ by volume brass coated steel fibers with $6 \mathrm{~mm}$ length and a diameter of $0.15 \mathrm{~mm}$ were used; the tensile strength of the fibers is 2200Mpa. The mixture proportions are shown in Table 3.

The AT-G, AT-B, AT-I were designed to investigate the aggregate type (AT) on the influence of the ultra-high performance cementitious materials. The AS-10, AS-15 and AS20 were used to study the effect of aggregate size (AS). The three different maximum aggregate size of $10 \mathrm{~mm}, 15 \mathrm{~mm}$ and $20 \mathrm{~mm}$ were investigated. As the aim of the study is the effect of aggregate type and maximum aggregate size, the volume fraction of coarse aggregate has to remain constant and has been chosen to a value of $27.5 \%$.

\subsection{Specimens preparation}

The cementitious materials (Portland cement, silica fume, fly ash and slag) and river sand were first dry-mixed for 1 minute. Then the mixture of water and surperplasticizer was added and mixed for 3 minutes. After that, the steel fiber was sprinkled slowly into cementitious mixture and mixed for another $3 \mathrm{~min}$ to make the steel fiber homogenously distributed through the fresh mortar. Finally, the coarse aggregates were poured into cementitious mixture and mixed for another 1 minutes. Then, the fresh C200
UHPC was cast into steel moulds and compacted by a vibrating table. The specimens were de-moulded after 24 hours, and then cured in the condition of $20^{\circ} \mathrm{C}$ and $98 \%$ relative humidity.

\subsection{Testing methods}

\subsubsection{Slump tests}

Fresh UHPC mixture properties were determined using the slump test for workability in accordance with China code of GB/T 50080-2016 [11]. The testing apparatus consisted of a normal slump cone and a steel plate with dimensions of $1000 \mathrm{~mm} \times 1000 \mathrm{~mm}$.

\subsubsection{Static tests}

A closed-loop servo-controlled material testing machine (MTS) was used to conduct compressive and flexural test. The compressive strength test was performed on $100 \times 100 \times 100 \mathrm{~mm}$ cubic specimens and the loading rate was $1 \mathrm{Mpa} / \mathrm{s}$. Flexural strength test was performed on $100 \times 100 \times 400 \mathrm{~mm}$ prismatic specimens by using thirdpoint loading and the span length of the specimen was $300 \mathrm{~mm}$, which is in accordance with China code of $\mathrm{GB} / \mathrm{T}$ 50081-2002 [12].

The compressive strength and flexural strength of C200 UHPC were conducted on 7, 14, 28 and 90 days age. Three specimens of each batch were tested and the average value was served as the final compressive strength and flexural strength. 


\subsubsection{Microscopic test}

In order to investigate the detail of the interfacial transition zone (ITZ) between the aggregate and paste, the MIP, SEM and XRD measurement were conducted. After the static test, the sample were obtain from the broken specimens. The hydration reaction of the cement paste was stopped by crushing the specimens into pieces of about 3$5 \mathrm{~mm}$ size, and then immersing them in acetone for $24 \mathrm{~h}$. After that the paste sample was dried at $40^{\circ} \mathrm{C}$ for $3 \mathrm{~h}$, and next placed in vacuum desiccators for 2 days, and then used for testing.

The specimens for SEM were mounted onto aluminium stubs using double-sided adhesive carbon discs and coated with gold. To ensure that electrical charge surfaces, a line of silver paint was applied connecting the specimen sides to the stub.

\section{Results and Discussion}

\subsection{Workability}

The slump of the ultra-high performance cementitious composite with different type of aggregate are shown in Figure 1. It clearly can be seen in Figure 1 that the AT-B and AT-G has a slump of $195 \mathrm{~mm}$ and $200 \mathrm{~mm}$, respectively. However, AT-I mixture which containing iron ore showed the lowest slump of $160 \mathrm{~mm}$. This may be attributed to the fact that iron ore aggregate has the highest water absorption capacity than other coarse aggregate. Just as shown in Table 2, the water absorption of CG, CB and CI is $0.28 \%$, $0.54 \%$ and $2.2 \%$, respectively. Therefore, more free water

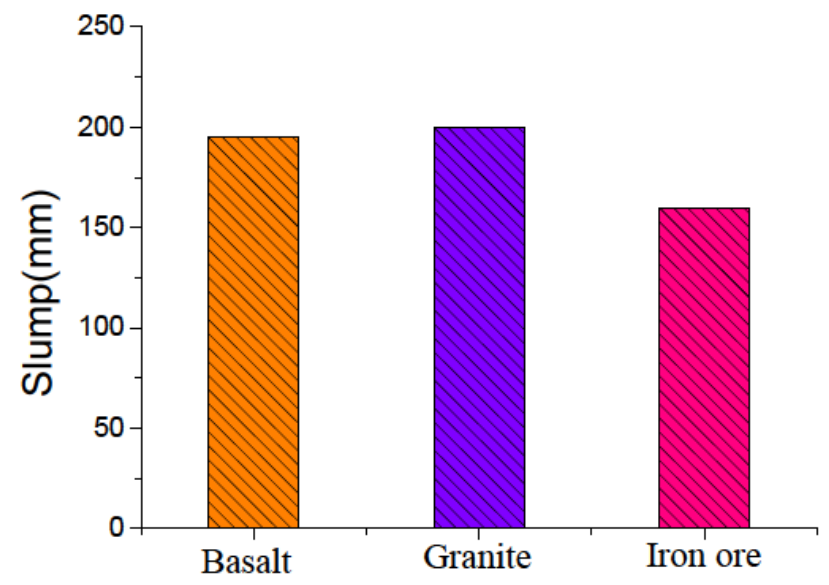

Figure 1: Influence of aggregate type on workability are absorbed into iron ore aggregate, thus reduce slump of AT-I mixture.

Besides, the density of the iron ore is $4.8 \mathrm{~g} / \mathrm{cm}^{3}$, which is larger than the density of basalt and granitic. Therefore, the heavy coarse aggregate of iron ore precipitated when conducting the slump test. The precipitation of the iron ore coarse aggregate may block the flow of the mixture.

The slump of the mixture with different maximum size of coarse aggregate are shown in Figure 2. The Figure 2 indicates that the slump values of the mixtures with smaller maximum size of coarse aggregates is higher than that with lager maximum size of coarse aggregate. This agrees with the study carried out by Uysal [13] and Szczesniak et al. [14] who investigate the self-compacting concrete (SCC).

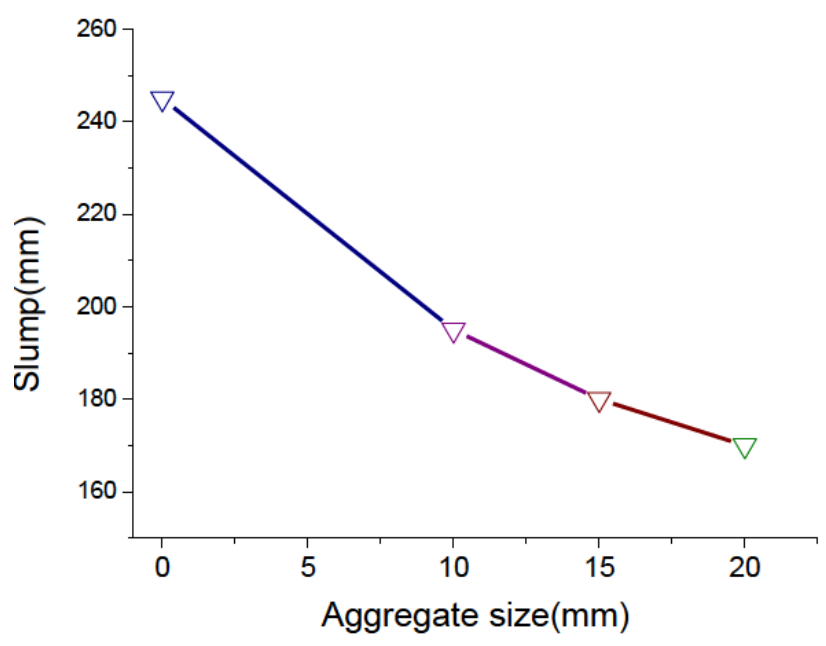

Figure 2: Influence of coarse aggregate size on workability

This phenomenon is reversed with the normal strength concrete (NSC). For a given aggregate fraction in the NSC, the workability improves as the size of the maximum aggregate particles increases, probably because of the decrease in specific surface [15]. This difference may be attributed to the different volume fraction of the paste between the C200 UHPC and NSC. Just as shown in Table 2, the volume fraction of paste in C200 UHPC is about $50 \%$. It is well known that the volume fraction of the paste in NSC is just only $15 \%$. Therefore, there is much excess paste in the C200 UHPC even with the small maximum size of coarse aggregate.

\subsection{Compressive strength}

The compressive strength development of UHPC mixtures without and with various types of coarse aggregates are 
presented in Figure 3. The data in Figure 3 indicates that the use of coarse aggregate have obvious influence on the compressive strength of UHPC. Just as shown in Figure 3, the compressive strength of UHPC with basalt aggregate is $203 \mathrm{MPa}$, which is higher than the 196MPa of UHPC without aggregate. However, the compressive strength of UHPC with granitic and iron ore coarse aggregate is $179 \mathrm{MPa}$ and $175 \mathrm{MPa}$, respectively. Therefore, it can be concluded that the basalt coarse aggregate have the positive effect on the compressive strength of UHPC. This phenomenon is different from the normal strength concrete. For normalstrength concrete, the effect of the type of coarse aggregate on the compressive strength is not significant [16].

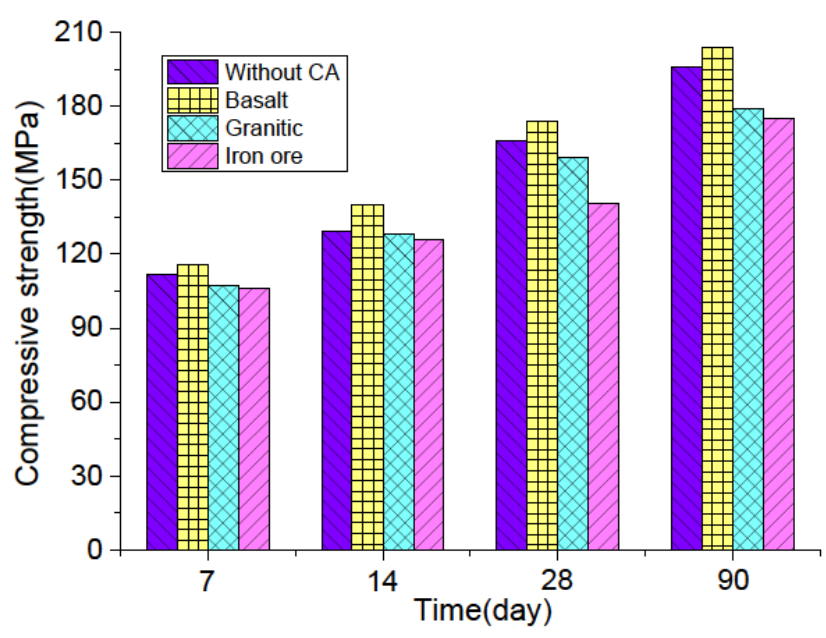

Figure 3: Influence of coarse aggregate type on compressive strength

It is well known that concrete is a composite, and its properties depend on the properties of the component phases (paste matrix and aggregate) and the interfacial transition zone (ITZ) between them. For the normal strength concrete, the compressive strength of paste matrix is low and the ITZ is weak [17]. The cracks exist in ITZ is a considerable extent before the concrete subjected to any external load. Under load, these small or microscopic cracks extend and interconnect, until, at ultimate load, the whole internal structure is completely disrupted [16]. The aggregate had, in comparison with concrete, relatively high strength and their potential strength was not fully used. Therefore, the type of the coarse aggregate has not obvious effect on the compressive strength of normal strength concrete. However, in UHPC, the strength of paste matrix and ITZ are extremely improved because of the very low water-to-binder ratio and the use of the mineral admixture including silica fume, fly ash and slag (the enhancement mechanism of UHPC ITZ will be discussed in section 3.4). Under load, the cracks may extend through the aggregate, which make use of the full strength potential of the coarse aggregate particles, just as shown in Figure 4. Therefore, the coarse aggregate presents positive effect in the strength of UHPC.

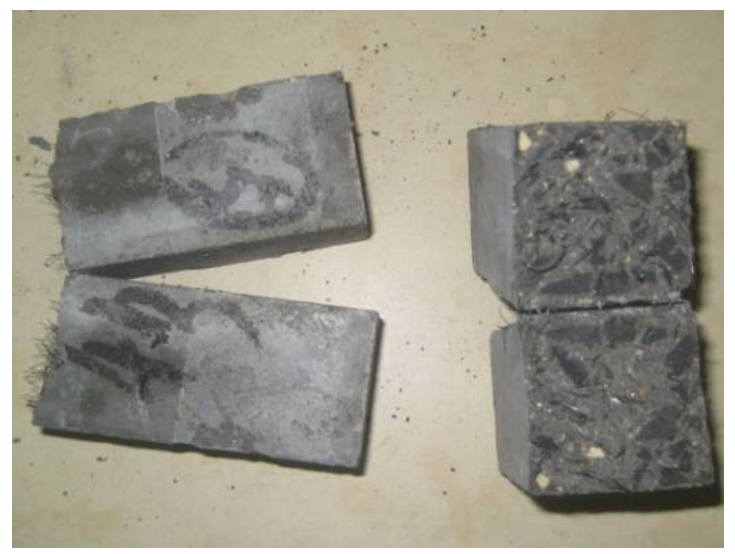

Figure 4: Fracture of the specimen

Besides, the data in Figure 3 also reveal that the type of coarse aggregate has a significant effect on the compressive strength of UHPC. The highest compressive strength of 203MPa were measured in UHPC mixture presented with basalt aggregate while the lowest compressive strength of $175 \mathrm{MPa}$ were noted in mixture prepared with iron ore coarse aggregate at 90d. The highest compressive strength of AT-B may attribute to the hard texture and rough surface of the basalt. For the AT-I, just as the discussion in section 3.1, it is hard to fabricate a homogenous UHPC mixture when adding the iron ore aggregate because of its high density.

The compressive strength of four UHPC with different maximum size of basalt coarse aggregate are shown in Figure 5 , the test results indicate that the maximum size of coarse aggregate has a significant influence on the compressive strength of UHPC. The UHPC with maximum size of $15 \mathrm{~mm}$ presents the highest compressive strength than other size at early curing age ( $7 \mathrm{~d}$ and $14 \mathrm{~d})$. However, the UHPC with maximum size of $10 \mathrm{~mm}$ shows the highest compressive strength at later curing age (28d and 90d). Besides, the compressive strength of the UHPC with $10 \mathrm{~mm}$ maximum size of coarse aggregate is $4.0 \%$ higher than the UHPC without aggregate. But the compressive strength of UHPC with $15 \mathrm{~mm}$ and $20 \mathrm{~mm}$ maximum size of aggregate is $4.5 \%$ and $6.6 \%$ lower than reference mixture, respectively. It can be concluded that the proper maximum size of coarse aggregate is helpful for the compressive strength 
of UHPC, but too large size of coarse aggregate tends to reduce UHPC strength. This is in agreement with the results of high performance concrete tests conducted by Aulia and Deutschmann [18].

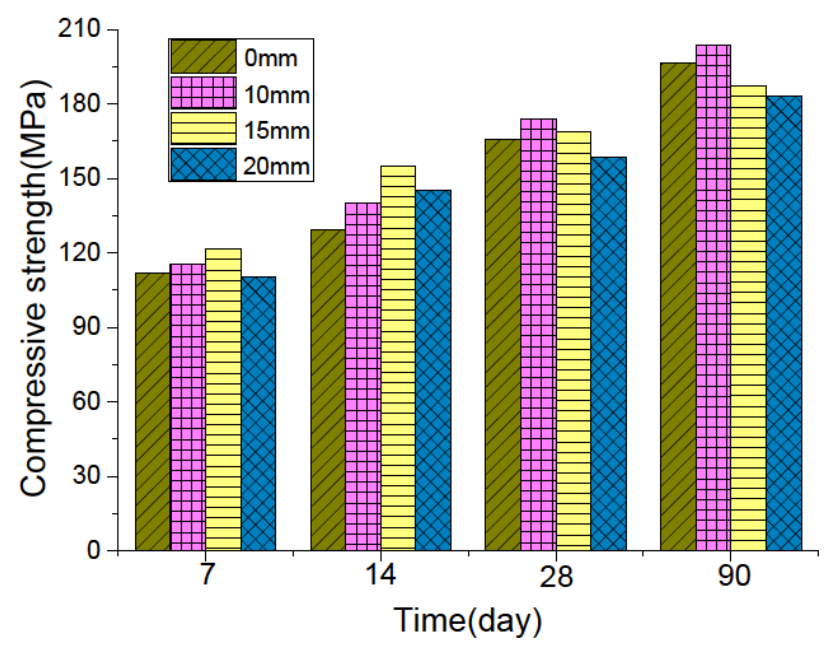

Figure 5: Influence of maximum size of aggregate on compressive strength

This is due to the smaller maximum size of coarse aggregate that has the larger surface area that results in a higher bonding strength in the transition zone around aggregate particles when UHPC is under loading [14]. The bond with large particles tends to be weaker than small particle due to smaller surface area-to-volume ratios. The increase in strength with lower diameter can probably be attributed to a change in the stress repartition inside the specimen. Each aggregate, which acts as a rather rigid inclusion inside a deformable matrix, will tend to restrain the contraction of the matrix under compressive load, comparatively to a specimen without rigid inclusions. Consequently, it will lead to a development of a locally non homogenous state of stresses around each inclusion, which depends on the aggregate diameter [19].

\subsection{Flexural strength}

Figure 6 shows the variation of flexural strength with age for the UHPC specimens prepared with the three types of aggregates selected for this study. As expected, the flexural strength increased with age in all of the UHPC specimens. Further, the data in Figure 6 indicate that the addition of coarse aggregate also has a significant effect on the flexural strength of UHPC. However, the effect is negative, which is different from the compressive strength discussed previously. Taking the $90 \mathrm{~d}$ for example, the compressive strength of UHPC without coarse aggregate is $54.5 \mathrm{MPa}$, which is $15 \%, 22.9 \%$ and $25.3 \%$ higher than that with basalt, granitic and iron ore coarse aggregate, respectively. The least flexural strength of specimens is the UHPC prepared with iron ore aggregate. This situation corresponds well with the normal strength concrete. Popovics [20] pointed out that the higher the elastic modulus of aggregate, the lower the flexural strength. Kaplan [21] also found that aside from texture and shape the modulus of elasticity that most affects compressive and flexural strengths of concrete. This may be attributed to the fact that too stiff an aggregate, though improving modulus, may cause stress concentration and initiate more mirocracking causing a decrease in strength [22].

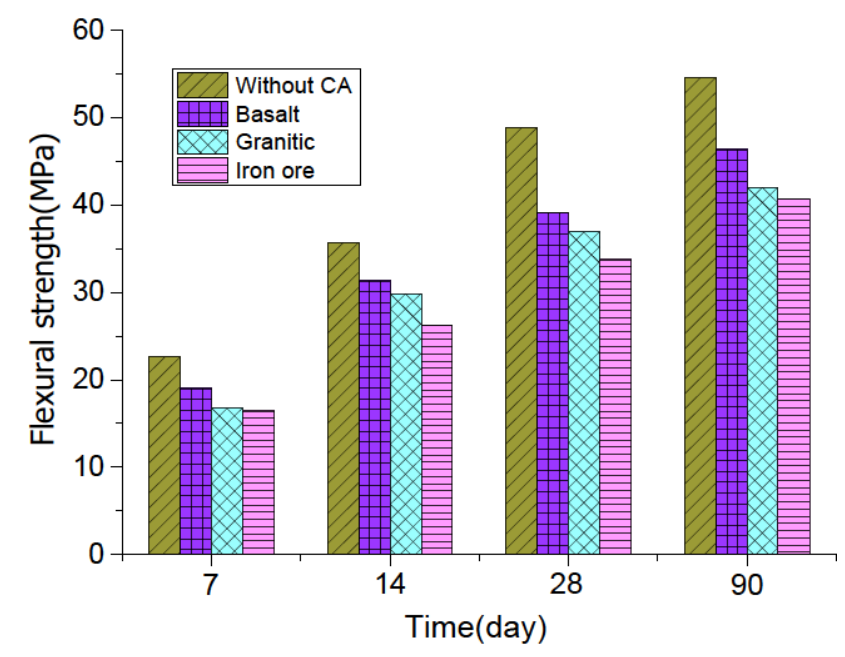

Figure 6: Influence of coarse aggregate type on flexural strength

Figure 7 shows the flexural strength of UHPC with different maximum size of basalt coarse aggregate. Note that in all cases, the flexural strength of UHPC with coarse aggregate is lower than without coarse aggregate, and the flexural strength seems to decrease as the aggregate size increases in all curing ages. Take 90d for example, the flexural strength of UHPC without coarse aggregate is $14.9 \%$, $27.5 \%$ and $32.1 \%$ higher than UHPC with maximum size of $10 \mathrm{~mm}, 15 \mathrm{~mm}$ and $20 \mathrm{~mm}$ coarse aggregates, respectively. This situation is different from the effect of maximum size of coarse aggregate on the compressive strength.

This trend, a decrease of the flexural strength with aggregate size increase, was also observed in normal strength concretes, as reported by Tasdemir et al. [23] and Li et al. [24]. However, tests performed by Chen and Liu $[25,26]$ on high-strength concretes show a reverse tendency with tensile strength increasing with the aggregate size. 
Table 4: Mercury intrusion porosimetry test results

\begin{tabular}{|c|c|c|c|c|c|}
\hline \multicolumn{4}{|c|}{ Pore size distribution (\%) } & \multirow[t]{2}{*}{ Average pore sie (nm) } & \multirow[t]{2}{*}{ Porosity (\%) } \\
\hline $\mathrm{d} \leq 20 \mathrm{~nm}$ & $20 \mathrm{~nm} \leq \mathrm{d} \leq 50 \mathrm{~nm}$ & $50 \mathrm{~nm} \leq \mathrm{d} \leq 200 \mathrm{~nm}$ & $\mathrm{~d}>200 \mathrm{~nm}$ & & \\
\hline 75.06 & 5.41 & 4.15 & 15.38 & 7.2 & 5.24 \\
\hline 11.82 & 28.13 & 51.37 & 8.68 & 55.2 & 18.7 \\
\hline
\end{tabular}

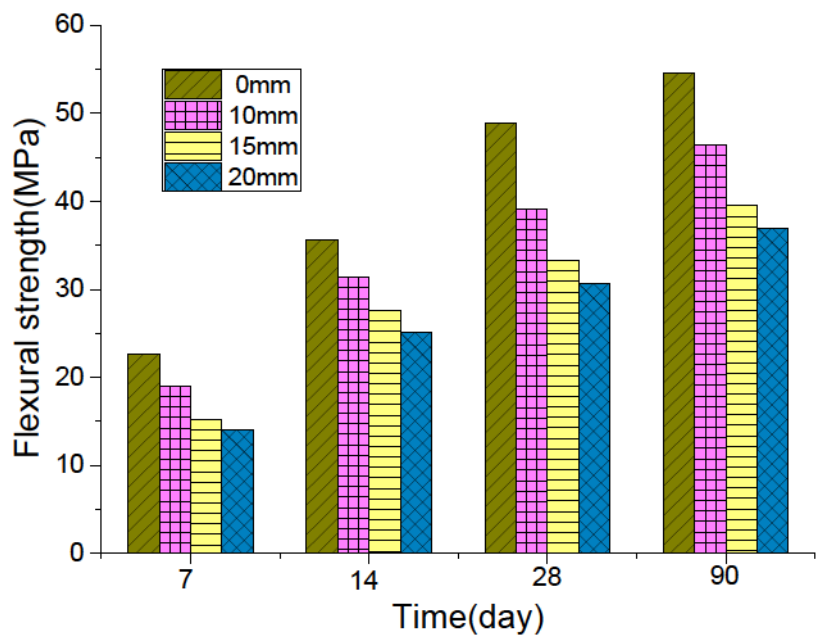

Figure 7: Influence of coarse aggregate size on flexural strength

The decrease of UHPC flexural strength as increase of maximum size of coarse aggregate may be explained by the followings. Although larger aggregates require less mixing water than smaller aggregates, the transition zone around larger aggregate is weaker. The larger aggregates provide larger fracture surfaces and more complicated cracking paths. Metha et al. [15] pointed out that the interfacial transition zone characteristics tend to affect tensile and flexural strength to a greater degree than compressive strength.

Basis on the above discussion of the mechanical properties, it can be concluded that the new UHPC may be prepared without any performance loss by use basalt coarse aggregate with maximum size of $10 \mathrm{~mm}$.

\subsection{Microstructure of the UHPC}

It clearly can be seen from the above discussion that the type and maximum size of coarse aggregate have significant influence on mechanical properties of UHPC. However, those influences are different from it in conventional concrete. In order to reveal the mechanism of UHPC, a series of micro-tests were conducted. For the comparison between UHPC and NSC, the NSC with water-cement ratio of 0.40 was specially prepared.

\subsubsection{MIP test}

The UHPC and NSC specimens were tested by mercury intrusion porosimetry (MIP) measurement. The pore distribution curves are presented in Figure 8 and the tests data is shown in Table 4. A significant decrease in porosity and average pore diameter was observed in UHPC as compared to the reference NSC concrete. The total porosity and average pore diameter of UHPC obtained is $5.24 \%$ and $7.2 \mathrm{~nm}$, which is much lower than the reference NSC with the correspondent value of $18.7 \%$ and $55.2 \mathrm{~nm}$. Therefore, it clearly can be seen from the MIP tests that the UHPC has high dense matrix.

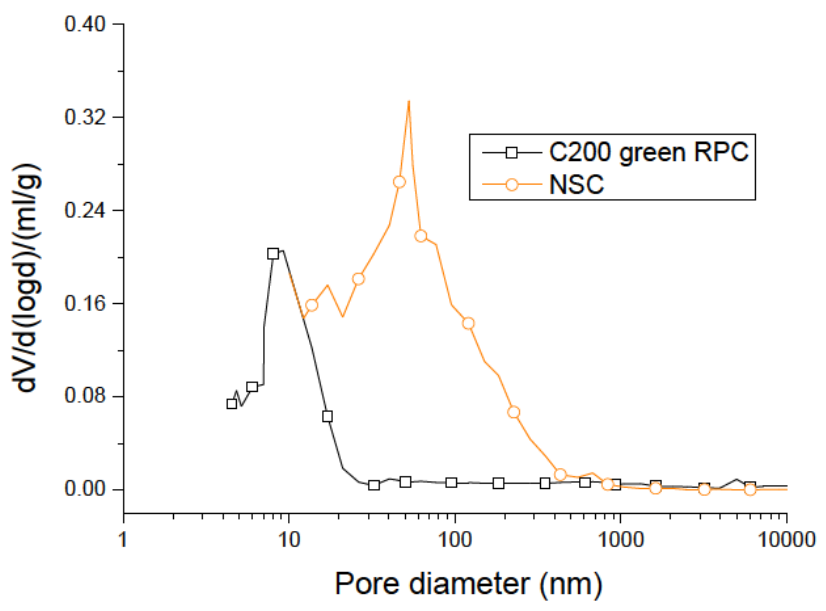

Figure 8: Differential pore size distribution curve

\subsubsection{ESEM test}

The ITZ of UHPC and normal strength concrete were studied by SEM tests, the picture is shown in Figure 9(a) and Figure 9(b), respectively. In Figure 9(a), the left side of the micrograph shows aggregates and the right presents paste matrix. The situation is reversed in Figure 9(b). It is apparent from Figure 9(a) that the weak ITZ completely vanishes and the bond between the coarse aggregate and UHPC paste is very dense and strong. However, the bond 
of the coarse aggregate and NSC paste is imperfect, and a gap with several pixels wide can be observed clearly, just as shown in Figure 9(b).

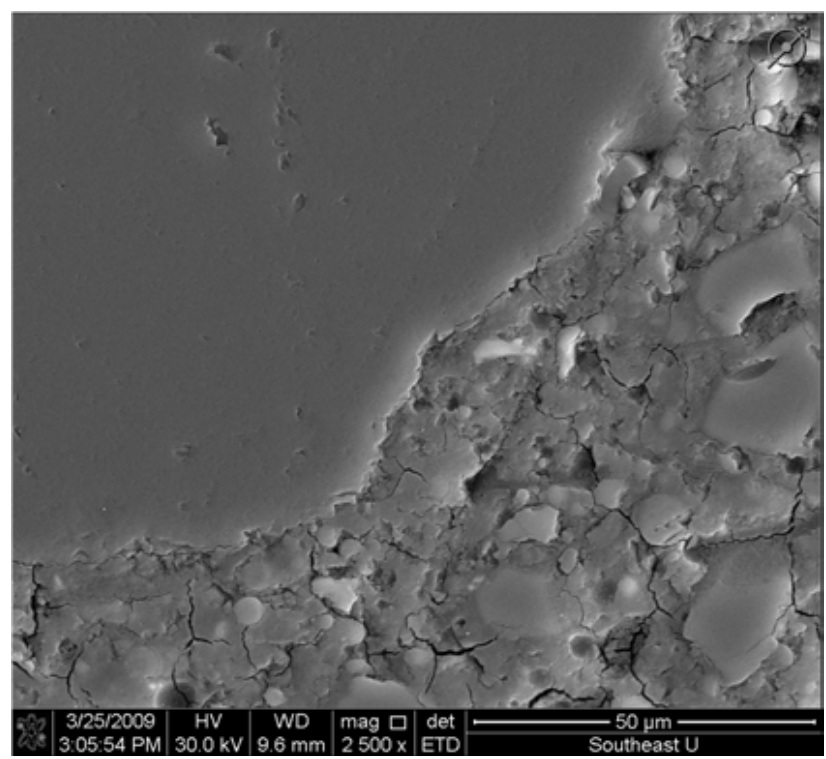

(a) C200 UHPC

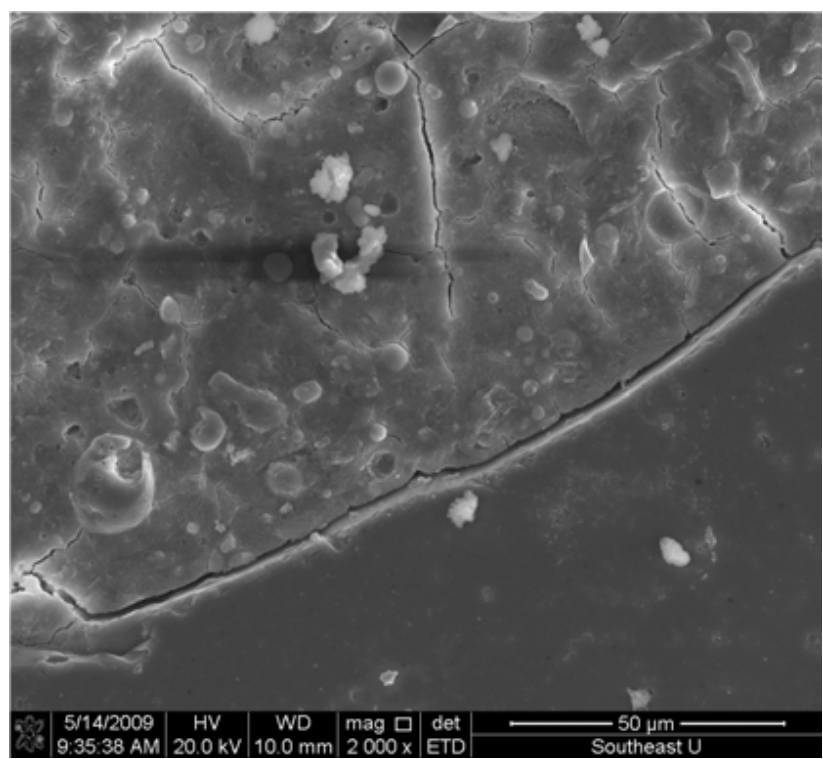

(b) NSC

Figure 9: SEM photos of ITZ

\subsubsection{XRD tests}

The XRD test were conducted on the specimens of UHPC and NSC. It can be seen that hydration products $\mathrm{CH}$ $(2 \theta=18.5,32.8,47.5)$ are formed in the NSC specimen. How- ever, obvious changes were observed in XRD spectrum of UHPC. The intensity of $\mathrm{CH}$ peaks is greatly reduced. This indicates pozzolanic reaction between $\mathrm{CH}$ and mineral admixtures (fly ash, slag, silica fume) takes place. Large amount of $\mathrm{CH}$ is eliminated and much C-S-H gel is formed. This reaction leads to obvious enhancement of the matrix and the ITZ of UHPC.

\subsubsection{Mechanism discussion}

Based on the micro-tests, the mechanical enhancement mechanism of UHPC are discussed. It is known that concrete is a composite, and its properties depend on the properties of the component phases and the interaction between them. The ITZ of normal strength concrete is a layer up to $50 \mu \mathrm{m}$ wide and characterized by a higher porosity with respect to the bulk cement paste [27]. In an higher contents of $\mathrm{CH}$ and ettringite with respect to the bulk cement paste, and much of the $\mathrm{CH}$ is considered to be preferentially oriented [28]. Therefore, the interfaces are the weakest link in concrete, playing a very important role in the process of failure.

However, the failure process of UHPC is much different from NSC. The coarse aggregate has much more significant influence on the UHPC mechanical properties than NSC. This phenomenon may be attributed to the following reasons.

Firstly, just as the MIP test results shown in Figure 8 and Table 4, the matrix of the UHPC is very dense and the porosity is low. This because of the use of surperplasticizer, the UHPC can be made with very low water-binder ratio (0.16 in this study) as well as keeping well workability. Besides, the particle size of the mineral admixture is small, which present the micro aggregate effect in the matrix of the paste. The space of the cement particle is highly compacted by the mineral admixture. Therefore, the very low porosity of the matrix leads to high strength of the C200 UHPC.

Secondly, just as the previous discussion, the ITZ are the weakest link in normal strength concrete, playing a very important role in the process of failure. However, the ITZ of the UHPC are extremely enhanced, just as shown in the SEM picture in Figure 9. The ITZ enhancement could be attributed to the pozzolanic action of mineral admixture includes silica fume, fly ash and slag. The main useful effect of the mineral admixture in UHPC consists of pozzolanic effect and micro aggregate effect. The silica fume, fly ash and slag mainly consist $\mathrm{Al}_{2} \mathrm{O}_{3}$ and $\mathrm{SiO}_{2}$ can be activated with calcium hydroxide and water to form compound with cementing properties. The two products of ce- 
ment hydration are calcium silicate hydrate (C-S-H) and calcium hydroxide (CH). C-S-H is the major contributor to concrete strength. The mineral admixture of silica fume, fly ash and slag contain the amorphous silica (S) which reacts with calcium hydroxide $(\mathrm{CH})$ to form additional C-S-H thereby improving the strength $[13,29,30]$. The XRD test results in Figure 10 prove that the content of the $\mathrm{CH}$ in $\mathrm{C} 200$ UHPC is much lower than pure cement. Besides, the micro aggregate effect of mineral admixture also play important role in the ITZ strength as well the matrix discussion as previous. Therefore, the ITZ in UHPC was enhanced extremely. The aggregate and the matrix works together and their potential strength may be fully used.

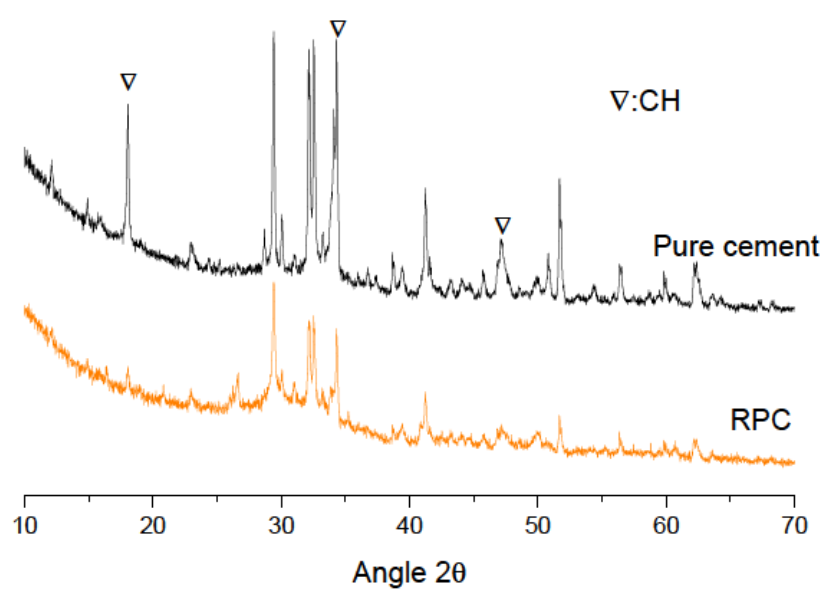

Figure 10: XRD patterns of UHPC and pure cement

\section{Conclusions}

Ultra-high performance concrete containing coarse aggregate with compressive strength of 200MPa (C200 UHPC) is successfully prepared in this study by utilizing composite mineral admixtures consisting of 10\% silica fume, $20 \%$ fly ash and $20 \%$ slag to replace $50 \%$ of Portland cement, using natural river sand with the maximal diameter of $3 \mathrm{~mm}$ to totally replace the ultra fine quartz sand, incorporating $3 \%$ volume fraction of small sized steel fibers, addition of the crashed basalt stone with maximum size of $10 \mathrm{~mm}$ as coarse aggregate, and employing low energy consumption curing regime of $20^{\circ} \mathrm{C}$ and $100 \% \mathrm{RH}$.

(1) The C200 UHPC with coarse aggregate has many advantages over conventional C200 RPC such as the low production cost, less energy consumption, easier preparation, and without any performance loss.
(2) The absorption of the coarse aggregate influence the workability of the fresh C200 UHPC. Besides, the workability decrease with the increasing of the maximum size of coarse aggregate.

(3) The type and maximum size of coarse aggregate has significant effect on the mechanical properties of C200 UHPC. The basalt coarse aggregate with maximum size of $10 \mathrm{~mm}$ has positive effect on the enhancement of compressive strength. However, the addition of coarse aggregate shows negative effect on flexural strength.

(4) The excellent properties of C200 UHPC are mainly attributed to proper design of the mixture with quaternary cementitious systems containing Portland cement, silica fume, fly ash and slag. The particle packing and filling effect, pozzolanic effect and microaggregate effect of the composites mineral admixtures result in a very compacted matrix and dense ITZ between the matrix and aggregate with low porosity and low $\mathrm{CH}$ content. The aggregate and the matrix works together and their potential strength may be fully used.

Acknowledgement: This research was financially supported by the National Natural Science Foundation of China (51678309, 51978339), State Key Laboratory of Silicate Materials for Architectures(Wuhan University of Technology), Priority Academic Program Development Jiangsu Higher Education Institutions (PAPD). Thanks Dr Su Fan and Dr Yang Jing of advanced analysis and testing center of Nanjing Forestry University for the help of the XRD and SEM tests.

\section{References}

[1] Richard P, Cheyrezy M. Composition of reactive powder concretes. Cement Concrete Res. 1995;25(7):1501-11.

[2] Zanni H, Cheyrezy M, Maret V, Philippot S, Nieto P. Investigation of hydration and pozzolanic reaction in Reactive Powder Concrete (RPC) using ${ }^{29}$ Si NMR. Cement Concrete Res. 1996;26(1):93-100.

[3] Bonneau O, Lachemi M, Dallaire E, A I Tcin PC, Dugat J. Mechanical properties and durability of two industrial reactive powder concretes. ACI Mater J. 1997;94(4):286-90.

[4] Cwirzen A, Penttala V, Vornanen C. Reactive powder based concretes: Mechanical properties, durability and hybrid use with OPC. Cement Concrete Res. 2008;38(10):1217-26.

[5] Blais PY, Couture M. Precast, prestressed pedestrian bridgeworld's first reactive powder concrete structure. Pci J. 1999; 44(5):60-71.

[6] Zhang YS, Sun W, Liu SF, Jiao CJ, Lai JZ. Preparation of C200 green reactive powder concrete and its static-dynamic behaviors. Cement Concrete Comp. 2008;30(9):831-38. 
[7] Zhang WH, Zhang YS, Zhang GR. Single and multiple dynamic impacts behaviour of ultra-high performance cementitious composite. Journal of Wuhan University of Technology-Mater Sci Ed. 2011;26(6):1227-34.

[8] Zhang WH, Zhang YS, Liu LB, Zhang G, Liu Z. Investigation of the influence of curing temperature and silica fume content on setting and hardening process of the blended cement paste by an improved ultrasonic apparatus. Constr Build Mater. 2012;33(1):32 40.

[9] Zhang WH, Zhang YS, Zhang GR. Static, dynamic mechanical properties and microstructure characteristics of ultra-high performance cementitious composites. Sci Eng Compos Mater. 2012;19(3):237-45.

[10] Zhang YS, Zhang WH, She W, Ma L, Zhu W. Ultrasound monitoring of setting and hardening process of ultra-high performance cementitious materials. NDT \& E Int. 2012;47(1):177-84.

[11] GB (2016) GB/T 50081-2016: Standard for test method of performance on ordinary fresh concrete. Ministry of Construction of the People's Republic of China. Beijing. China. (in Chinese).

[12] GB (2002) GB/T 50081-2002: Standard for test methods of physical and mechanical properties of concrete. Ministry of Construction of the People's Republic of China. Beijing. China. (in Chinese).

[13] Uysal M. The influence of coarse aggregate type on mechanical properties of fly ash additive self-compacting concrete. Constr Build Mater. 2012;37(1):533-40.

[14] Khaleel OR, Al-Mishhadani SA, Abdul Razak H. The Effect of Coarse Aggregate on Fresh and Hardened Properties of SelfCompacting Concrete (SCC). Procedia Engineering. 2011;14:80513.

[15] Mehta PK, Monteiro PJ. Concrete: Microstructure, Properties and Materials. 2005. New York: McGraw-Hill Professional.

[16] Wu K, Chen B, Yao W, Zhang D. Effect of coarse aggregate type on mechanical properties of high-performance concrete. Cement Concrete Res. 2001;31(10):1421-25.

[17] Beshr H, Almusallam AA, Maslehuddin M. Effect of coarse aggregate quality on the mechanical properties of high strength concrete. Constr Build Mater. 2003;17(2):97-103.
[18] Aulia TB, Deutschmann K. Effect of mechanical properties of aggregate on the ductility of high performance concrete. Lacer Leipzig. 1999;4(1):133-48.

[19] Szczesniak M, Rougelot T, Burlion N, Shao JF. Compressive strength of cement-based composites: Roles of aggregate diameter and water saturation degree. Cement Concrete Comp. 2013;37(1):249-58

[20] Popovices S. Concrete Making Materials. McGraw-Hill Book Company. 1979. New York: Hemisphere Publishing Corporation, Washington DC.

[21] Kaplan MF. Flexural and Compressive Strength of Concrete as Affected by the Properties of Coarse Aggregate. National Building Research Institute. South Africa. 1193-1208.

[22] Zhou FP, Lydon FD, Barr BIG. Effect of coarse aggregate on elastic modulus and compressive strength of high performance concrete. Cement Concrete Res. 1995;25(1):177-86.

[23] Tasdemir C, Tasdemir MA, Lydon FD, Barr BIG. Effects of silica fume and aggregate size on the brittleness of concrete. Cement Concrete Res. 1996;26(1):63-68.

[24] Li Q, Deng Z, Fu H. Effect of aggregate type on mechanical behavior of dam concrete. ACI Mater J. 2004;101(6):483-92.

[25] Chen B, Liu J. Effect of aggregate on the fracture behavior of high strength concrete. Constr Build Mater. 2004;18(8):585-90.

[26] Chen B, Liu J. Investigation of effects of aggregate size on the fracture behavior of high performance concrete by acoustic emis sion. Constr Build Mater. 2007;21(8):1696-1701.

[27] Alonso E, Martıńez L, Martıńez W, Villaseñor L. Mechanical properties of concrete elaborated with igneous aggregates. Cement Concrete Res. 2002;32(2):317-21.

[28] Diamond S, Huang J. The ITZ in concrete - a different view based on image analysis and SEM observations. Cement Concrete Comp. 2001;23(2-3):179-88.

[29] Hale WM, Freyne SF, Bush TD, Russell BW. Properties of concrete mixtures containing slag cement and fly ash for use in transportation structures. Constr Build Mater. 2008;22(9):1990-2000.

[30] Radlinski M, Olek J. Investigation into the synergistic effects in ternary cementitious systems containing portland cement, fly ash and silica fume. Cement Concrete Comp. 2012;34(4):451-59. 